\title{
TANTRISME DI DALAM AGURON GURON KAWIKON BUDHA PAKSA DI GRIA BUDAKELING
}

Oleh:

\author{
Ida Made Santi Utama, I Wayan Suka Yasa, I Wayan Budi Utama \\ Pascasarjana Universitas Hindu Indonesia \\ Denpasar \\ budiutama904@gmail.com
}

\begin{abstract}
This article discusses Tantrism applied within the system of aguron-guron kawikon budha paksa (type of buddhist school of priesthood) in Gria Budakeling. The Tantrism in this system of aguronguron is at the core of the priestly teachings of the Wajrayana Buddhist school, which has been going on since ancient times and inherited and preserved for generations by the descendants of the Gria Budakeling family from Dang Hyang Astapaka clan, a Kasogatan Buddhist Priest. As a Buddha paksa clergy system, the book Sang Hyang Kamahayanikan is the main handle book supported by some references of siwa paksa such as the book of silakramaning aguron-guron, silakrama, vrati sesana, siwa sesana and others. The Book of Sang Hyang Kamahayanikan is the ancient Tantric book. It contains the teachings of the philosophy of liberation, ministerial materials, and the rules of the relationship between Teacher (Nabe) and the spiritual students.
\end{abstract}

Keywords: Tantrism, aguron-guron, school system of priesthood

\begin{abstract}
Abstrak
Artikel ini membahas tentang Tantrisme di dalam aguron-guron kawikon budha paksa di Gria Budakeling. Tantrisme dalam aguron-guron kawikon budha paksa merupakan inti dari ajaran kependetaan dari mazhab budha wajrayana, yang telah berlangsung sejak jaman dahulu serta diwarisi dan dipertahankan secara turun temurun oleh keturunan dari keluarga Gria Budakeling yang merupan keturunan dari Dang Hyang Astapaka seorang Pendeta Budha Kasogatan. Sebagai sebuah system perguruan kependetaan budha paksa, kitab Sang Hyang Kamahayanikan merupakan pegangan utama ditambah kitab-kitab dari siwa paksa seperti kitab silakramaning aguron-guron, silakrama, vrati sesana, siwa sesana dan lain-lain. Kitab Sang Hyang Kamahayanikan merupakan kitab kuno yang bersifat Tantris. Memuat ajaran filsafat jalan pembebasan, materi kependetaan serta tata aturan hubungan Guru/Nabe dan murid kerohaniannya.
\end{abstract}

Kata kunci: Tantrisme, aguron-guron, sistem perguruan kependetaan

\section{PENDAHULUAN}

Kehidupan masyarakat Bali dewasa ini susungguhnya merupakan hasil suatu perkembangan sejarahnya yang telah dimulai sejak pulau kecil ini dihuni oleh manusia
Indonesia yang tertua, yang hidup mengembara pada masa berburu dan mengumpulkan makanan tingkat sederhana. Masa ini berlangsung cukup lama dan terjadi jauh sebelum datangnya pengaruh agama Hindu di Bali dan disebut masa prasejarah atau sering 
kali juga disebut masa pra Hindu, yaitu suatu masa ketika berlangsungnya kehidupan suatu masyarakat yang belum mengenal tulisan.

Setiap masyarakat mengalami masa prasejarah yang berbeda beda lamanya. Segala aspek kehidupan masyarakat Bali yang dapat disaksikan sekarang dijiwai oleh Agama Hindu yang dianut oleh sebagian terbesar penduduk pulau Bali. Kenyataan itu merupakan mata rantai yang tidak terputuskan dari sejarahnya, bahkan ketika kerajaan Majapahit runtuh pada abad ke 15, Agama Hindu di Bali tetap tetap berkembang sampai saat ini dan di Jawa Timur mengalami kemunduran. Menurut bukti-bukti yang ditemukan oleh para ahli pulau Bali mengakhiri masa pra sejarahnya pada sekitar abad ke 8 Masehi. Hal ini terbukti dengan ditemukannya stupika stupika dan materaimaterai tanah liat di Desa Pejeng (Gianyar), yang memuat mantra-mantra Agama Budha dan diduga berasal dari abad 8 Masehi. Perjalanan panjang masa prasejarah Bali dari masa berburu hingga masa perundagian ditemukan buktibukti sejarah dimana masyarakat memelihara babi disamping untuk konsumsi juga untuk keperluan upacara-upacara tertentu, disamping adanya suatu keyakinan didalam masyarakat bahwa kehidupan setelah kematian akan berpengaruh terhadap kehidupan di dunia ini.

Pada masa perundagian kepercayaan ini berkembang pesat dengan dilakukannya prosesi upacara penguburan orang meninggal dengan ritual khusus dan diberikan bekal kubur. Penemuan Nekara Bulan Pejeng pada masa perundagian juga merupakan bukti sejarah bahwa Bali memiliki peradaban yang tinggi pada masanya. Simbol-simbol atau hiasan yang terdapat pada Bulan Pejeng seperti pola bintang, hiasan bulu burung, pola tumpal yang tersusun, pola tumpal yang bertolak belakang, pola huruf $\mathrm{f}$, sepasang topeng dan sebagainya. Hal tersebut di samping merupakan karya seni yang indah namun juga memiliki nilai magis yang penting artinya bagi kehidupan masyarakat. Hiasan kedok muka yang disusun sepasang bermakna nenek moyang yang arwahnya selalu dipuja dan diyakini topeng tersebut memiliki kekuatan magis. Seperti diketahui bagian tertentu tubuh manusia seperti mata dan kelamin diyakini memiliki kekuatan magis yang besar yang dapat menolak segala rintangan yang dihadapi. Arwah nenek moyang dianggap bersemayam di puncak bukit atau gunung, hal tersebut terlihat dari orientasi arah sarkofagus yang bagian kepala mengarah pada gunung atau bukit yang terdekat.

Temuan megalit berbentuk sebuah Phalus di Pura Kaki Dukun di Desa Tenganan Pegringsingan Karangasem, serta temuan megalit megalit di tempat lain dengan penonjolan genetalia yang lengkap dengan bagian bagiannya sepeti temuan di Pura Pusering Jagat (Pejeng) yang berbentuk vagina dan phalus. Simbol-simbol tersebut adalah mewakili kepercayaan masyarakat pada saat itu yaitu meyakini keberadaan roh nenek moyang serta adanya kepercayaan kepada alat kelamin manusia memiliki kekuatan magis. Bisa disimpulkan bahwa pada masa pra sejarah masyarakat Bali telah memiliki system kepercayaan dan tempat pemujaan. (Sutaba, 1980: 19).

Secara umum Bangsa Indonesia memiliki lokal genius termasuk dalam bidang keagamaan. Istilah lokal genius pertama kali diperkenalkan oleh Quaritch Wales, menurutnya kemampuan kebudayaan setempat dalam menghadapi pengaruh kebudayaan asing pada waktu ke dua kebudayaan itu berhubungan. Sebagai akibat dari hubungan itu terjadilah akulturasi budaya, dimana kebudayaan setempat menerima pengaruh kebudayaan asing. Pengertian tersebut diperoleh dari pengamatannya atas hubungan yang terjadi pada waktu kebudayaan Indonesia menerima pengaruh kebudayaan India. Ia melihat bahwa kebudayaan di Indonesia bagian barat menerimanya secara penuh, sehingga terlihat meniru belaka kebudayaan India. Sebaliknya di Indonesia bagian timur kebudayaan India itu hanya sebagai perangsang bagi perkembangan kebudayaan setempat. Dalam hal ini ia (Quaritch Wales) melihat dalam kebudayaan setempat itu, yaitu kebudayaan pra sejarah tetap mampu mempertahankan salah satu unsur kebudayaan yaitu ragam hias geometris. Kemampuan inilah yang secara nyata ia maksudkan sebagai local genius. Sarjana lain yang mengembangkan lebih lanjut tentang local genius adalah Bosch. Berbeda dengan Quaritch Wales, Bosch lebih menitikberatkan pada pelaku penerima budaya itu sendiri. Menurut pendapatnya, proses penerimaan kebudayaan itu dilakukan oleh para pendeta Indonesia. Para pendeta ini mula-mula belajar ke India serta kemudian kembali ke Indonesia. Setibanya di Indonesia mereka lalu mengamalkan ilmu yang 
mereka peroleh. Hasil pengamalan mereka yang sampai kepada kita sekarang antara lain adalah candi dan karya sastra. Ditinjau dari teori kebudayaan, kedua pendapat di atas melihat local genius dari perwujudannya, yaitu dari kebudayaan materi atau kebudayaan fisiknya. Sebaliknya dalam tulisan ini akan dicoba untuk mengkaji pengertiannya ditinjau dari sudut atau sebagai sistem budayanya. Setelah diketahui sistem budayanya barulah kemudian ditinjau bagaimana sistem itu diwujudkan sebagai kebudayaan materi. Adapun pengertian local genius yang hendak dikembangkan adalah pengertian Bosch. Dengan demikian maka pengertiannya adalah kemampuan untuk mempelajari, menghayati, serta kemudian mengelolanya kembali dan merumuskannya sebagai suatu konsep yang baru. Mengingat bahwa kebudayaan yang dibicarakan itu berasal dari masa kebudayaan bangsa Indonesia memeluk agama Budha dan Hindu atau yang lebih dikenal sebagai masa klasik, kebudayaan itu sangat ditentukan oleh agama, maka yang dirumuskan itu adalah ajaran agama. Akhirnya perumusan berupa rekontruksi ajaran agama itu, sebagai hasil interpretasi menurut kebudayaan Indonesia diwujudkan sebagai karya sastra atau bangunan keagamaan dalam bentuk candi. (Ayatrohaedi, 1986: 18).

Jelas dari uraian tersebut diatas bangsa kita mengalami masa dimana hadirnya pengaruh Kebudayaan India dan adanya proses seleksi oleh local genius yang nantinya membentuk kebudayaan yang bersifat akulturasi.

Budhisme dan Siwaisme yang berkembang di Indonesia merupakan konsekwensi langsung dari adanya kontak kebudayaan antara kebudayaan India dan kebudayaan Indonesia pada masa kuno. Kontak ini telah berlangsung dengan sangat meyakinkan dalam gelombang penyebaran kebudayaan India ke wilayah Asia Tenggara pada permulaan tarikh masehi. Berbagai faktor menyuburkan imigrasi kultural ini ke wilayah yang luas termasuk Indonesia. Pengaruh ini terasa sangat besar dan telah meresap sangat dalam didalam masyarakat yang terdiri dari berbagai suku, bahasa, system kepercayaan, adat istiadat yang bhinneka di wilayah ini. Jejak-jejaknya dapat dilihat dan dirasakan telah ikut memperkaya kebudayaan nasional. Kehadiran kebudayaan India di wilayah nusantara ini merupakan tonggak penting dalam perjalanan sejarah bangsa Indonesia, karena dengan ini bangsa Indonesia mengenal aksara, melahirkan karya sastra dan filsafat dan memasuki masa sejarah. Ada karakter umum yang dapat ditemukan pada semua wilayah ini. Kemampuan selektivitas dan adaptasi pemikiran local genius wilayah-wilayah tersebut dan ditambah dengan alam pemikiran India yang mengembangkan pluralisme kebudayaan, maka pengaruh India mengambil wujud yang tidak sama dengan tempat asalnya. Hubungan yang menyebabkan terjadinya pengaruh nilai-nilai India yang meluas di beberapa pulau di Indonesia terasa dominan menyentuh aspek-aspek agama, seni, sastra, arsitektur, system pemerintahan, tatanan sosialkemasyarakatan dan lain-lain. Hinduisme dan Budhisme yang lahir di bumi India secara pasti telah berkembang di Indonesia dan pernah menjadi agama negara pada jamannya. Agama Buddha menjadi agama negara dalam Kerajaan Sriwijaya di Sumatera abad ke-7 Masehi, Agama Hindu tepatnya Siwa-Buddhagama menjadi agama negara dalam Kerajaan Majapahit di Jawa Timur pada abad ke-14. (Suamba, 2007).

Dasar-dasar ajaran Tantrayana yang memposisikan pemujaan terhadap perempuan (sakti) sebagai sesuatu yang sangat penting, telah ditemukan jauh sebelum pengaruh agama Hindu berkembang di India. Temuan temuan yang dihasilkan dari penggalian di Daerah Mahenjodaro dan Harrapa antara lain arca terracotta yang menggambarkan tubuh wanita dengan pinggang ramping, pinggul dan buah dada yang penuh sebagai gambaran wanita yang subur, telah mengantarkan para ahli untuk berasumsi bahwa orang orang Dravida sebagai pendukung kebudayaan ini lebih mengutamakan pemujaan terhadap Dewi (Sakti). Catatan terpenting dari ajaran Tantrayana adalah memberikan posisi sentral pada Sakti (Parvati) sebagai aspek pradhana dari Siwa.

Melihat kandungan unsur unsur tantra dalam tradisi Hindu Bali yang terhampar luas perlu kiranya dilakukan penelitian untuk mendapatkan gambaran yang benar serta memahami manfaat dan hakekat ajaran tantra dalam peradaban spiritual Bali yang kini mulai memsuki era masyarakat praktis dan tidak mengakar kuat pada budaya leluhurnya. Hal tersebut sangat berbahaya dalam upaya mengawal dan menjaga kelestarian ajaran 
ajaran luhur tersebut. Jejak jejak tantra di Bali banyak dijumpai, seperti pada Pura Kebo Edan dijumpai arca-arca dengan pahatan phallus (seks laki-laki) yang sangat besar. Kemudian peninggalan di Pura Dalem Tamblingan berupa batu monolit dengan lubang disertai satu batu berbentuk silinder tertancap pada lubang tersebut. Peninggalan ini oleh masyarakan disebut Celak Kontong Lugeng Luwih, celak kontong adalah simbol seks laki-laki sedangkan lugeng luwih adalah symbol seks perempuan. Pertemuan kedua unsur ini merupakan lambang Kesuburan. Peninggalan peninggalan serupa bisa dijumpai di Pura Dalem Celuk Buruan, di Pura Pusering Jagat, di Pura Kaki Dukun Tenganan Pegringsingan. Konsep-konsep lokal di atas merupakan tempat yang ideal bagi pencangkokan ajaran Tantrayana.

Dengan masuknya agama-agama India maka dikenallah jalan dua arah, yakni "Tuhan turun kepada manusia, dan manusia naik menuju Tuhan". Ajaran "naik turun" ini dalam rangka hubungan penyatuan manusia dengan "Tuhan" ini, terdapat dalam ajaran 'Tantrayana'. Tujuan Tantrayana adalah jiwanmukti (meraga sukma) yakni pembebasan diri sementara dalam hidup ini dengan usaha diri sendiri. Seorang tantris tidak hanya menguasai energy diri sendiri yang tersimpan dalam tubuhnya, tetapi juga menguasai energy universal, sebab mikrokosmos manusia adalah satu zat dengan makrokosmos semesta, sehingga mencapai tingkat kesempurnaan secara spiritual. Tantrayana menghubungkan tubuh dengan semesta melalui cakra atau pusat. Jejak-jejak tantrayana di Bali sangat mudah kita jumpai dalam pelaksanaan tradisi berupacara yang merupakan pelaksanaan Panca Yadnya, seperti upacara pekala kalaan dalam pernikahan dimana symbol yoni dilambangkan dengan tikeh dadakan yang nantinya akan ditusuk dengan keris sebagai symbol lingga oleh pihak laki-laki, kemudian penggunaan symbol tipat bantal dan banyak lagi yang lainnya. (Utama, 2014).

Sebuah desa diujung timur pulau Bali menyimpan sejarah panjang perjalanan peradaban Tantra di Nusantara ini, desa tersebut bernama Desa Budakeling yang merupakan bagian dari wilayah Kecamatan Bebandem Kabupaten Karangasem. Di tengah desa tersebut terdapat komunitas brahmana budha yang secara garis keturunan merupakan Trah dari
Dang Hyang Astapaka seorang wiku dari paham Budha Mahayana dari tanah Jawa. Keturunan beliau inilah yang menjaga dan merawat tradisi kependetaan Brahmana Budha sampai saat ini. Kehadiran beliau di tanah Bali diperkirakan pada abad 14 saat diutus oleh ayah beliau yaitu Dang Hyang Nata Angsoka untuk memenuhi undangan Raja Bali Ide Dalem Waturenggong dalam rangka untuk memimpin karya Homa di Pura Besakih bersama paman beliau Dang Hyang Nirartha.

Dalam perjalanan beliau setelah upacara Homa selesai, sampailah beliau di Desa Budakeling, di tempat inilah beliau membangun pasraman sampai beliau moksah. Warisan tradisi kependetaan turun temurun terus dijalankan dalam bentuk Sesana Aguron Guron. Serta Budakeling dikenal luas sebagai pusat Brahmana Budha di Bali. (Kantor Kepala Desa Budakeling, 2017).

Secara umum dari uraian diatas dan dari pengamatan di lapangan dapat diketahui bahwa paham Tantrisme begitu kuat terlihat dari masa Bali Pra Hindu sampai masa Hindu-Budha. Dalam praktek-praktek sitem kepercayaan, upacara atau ritual, kependetaan, cerita rakyat dan budayanya. Namun tidak banyak masyarakat sekarang yang memahami hal tersebut.

\section{PEMBAHASAN}

\subsection{Aspek Kesejarahan}

Apabila dilihat dari aspek kesejarahan system aguron-guron di Gria Budakeling merupakan warisan dari para pendauhulunya atau disebut juga warisan para leluhur. Hal ini sesuai dengan pernyataan informan yaitu Ida Pedanda Gede Nyoman Jelantik Dwaja dari Gria Jelantik Dauh Pasar Budakeling serta Ida Pedanda Gede Putra Kawan dari Gria Kawan Budakeling, dijelaskan bahwa praktek tantrisme di dalam aguron-guron kawikon budha paksa di Gria Budakeling merupakan pakem yang telah diwariskan secara turun temurun oleh para pendahulu. Disini dapat dijelaskan bahwa leluhur orang Gria Budakeling adalah merupakan keturunan dari pendeta dari paham Budha di era majapahit.

Apabila meninjau keberadaan paham Tantrisme didalam ajaran Buddha Mahayana (wajrayana) secara aspek kesejarahan berdasar peninggalan susastra klasik berbahasa Jawa kuno maka menurut buku " Siwa-Budha di 
Silsilah

\section{Dang Hyang Astapaka Kamimitan Brahmana Budha Budhakeling}

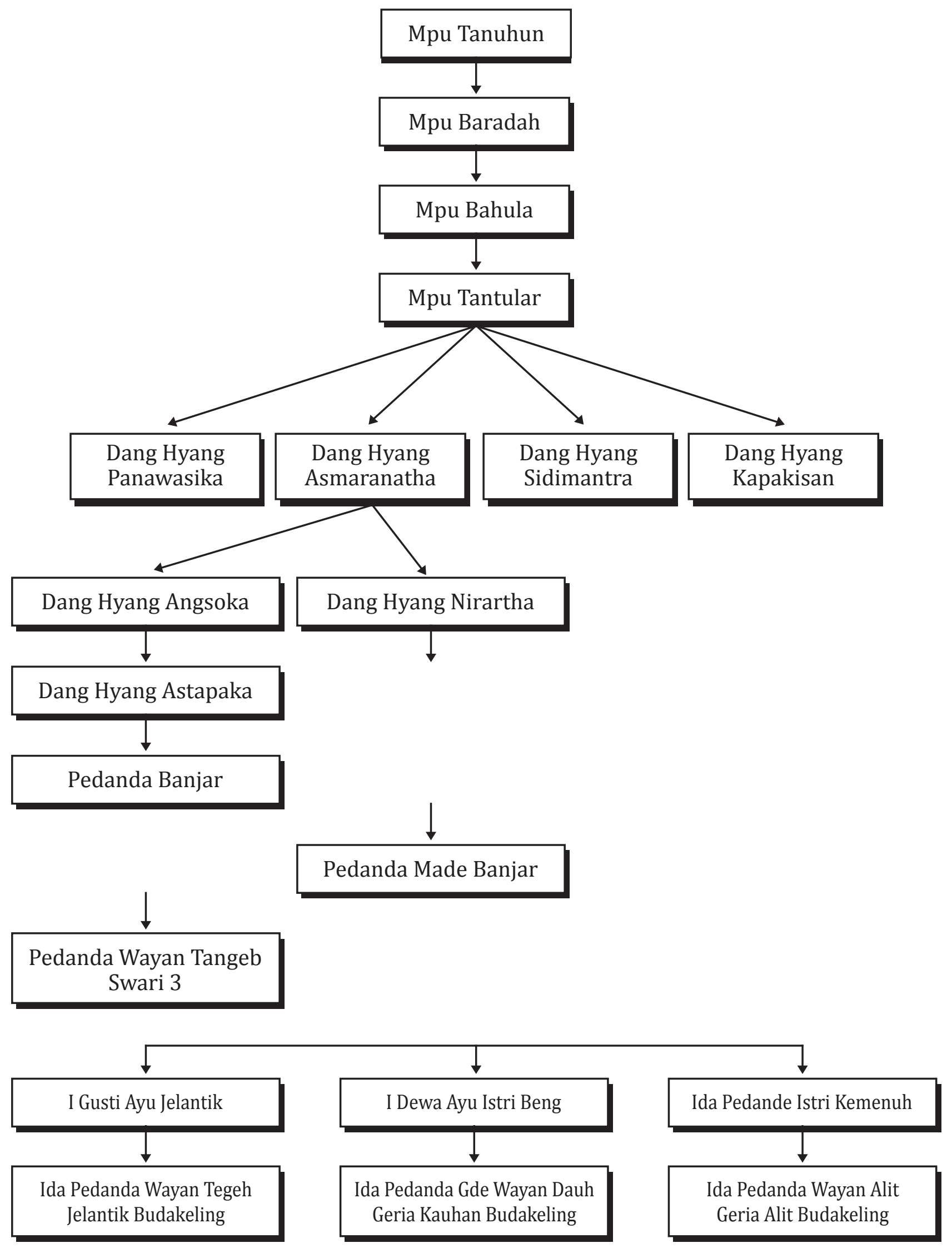


Indonesia Ajaran dan Perkembangannya, oleh I.B. Suamba, 2007" dapat diuraikan sebagai berikut, bahwa perjalanan evolusi ajaran SiwaBuddha terekam dalam sejumlah bukti-bukti prasasti, piagam dan teks yang mengungkap aspek-aspek metafisika, teologi maupun agama.

Bukti-bukti teks sastra memberikan informasi yang cukup memadai untuk melihat system filsafat di dalam agama ini, sementara bukti-bukti prasasti bersifat fragmentaris sehingga sukar mengkontruksi system filsafatnya. Bukti-bukti teks berupa karya-karya sastra berbahasa Jawa Kuno itu merupakan rekaman dinamika kegelisahan kreatif dan pencarian spiritual para Mpu, Acarya, Pendeta di Jawa Tengah, Jawa Timur dan kemudian berlanjut di Bali. Ada sejumlah karya-karya Sastra Jawa Kuno yang menggambarkan proses penunggalan kedua agama ini sejak era Jawa Tengah dan Jawa Timur.

Khusus menyangkut pengaruh ajaran Tantra maka dapat dilihat bahwasanya keusasteraan tutur (tutur literatures) berbahasa Jawa Kuno (Kawi) adalah teks-teks yang membahas masalah-masalah filsafat, agama dan yoga. Tekteks ini sangat diwarnai oleh ajaran Tantra atau mempunyai nuansa Tantrik yang kuat. Adapun teks-teks yang mengandung bukti ajaran SiwaBudha adalah : Sanghyang Kamahayanikan, Arjuna Wijaya, Sutasoma, Negarakrtagama, Kunjarakarna, Tantu Pagelaran, BubuksahGagak Aking.

\subsection{Aspek Sastra}

Merupakan sebuah ciri atau identitas dalam praktek kependetaan di Bali dimana terkandung unsur-unsur ajaran Ketantraan di dalamnya. Hal tersebut bisa dilihat dari praktek-prakteknya serta kitab-kitab yang menjadi pegangan para pendeta. Dengan perjalanan panjang peradaban Siwa-Budha di Bali dan Nusantara yang membentuk peradaban akulturasi dengan system keyakinan local, bukanlah hal yang mudah untuk memilah kembali pada bagian mana unsur tantra tersebut masih melekat. Apalagi dalam praktek yadnya di Bali kedua pendeta dari paham berbeda tersebut sudah saling mengisi dalam memimpin tiap upacara yadnya. Dominasi paham Siwa turut memberi sumbangsih dalam peleburan dua paham kependetaan tersebut.

Merujuk kitab Sanghyang Kamahayanikan terbitan Proyek Penterjemahan Kitab Suci Hindu dan Buddha Departemen Agama R.I. tahun 1973 disebutkan salah satu bentuk Madzab yang timbul dalam Madzab Mahayana dan merupakan ajaran Agama Buddha, ialah Madzab Tantrayana yang juga dikenal dengan Madzab Mantrayana. Perkembangan Madzab Tantrayana ini merupakan akibat langsung yang timbul dari pengaruh Madzab Ciwaisme dari Agama Hindu. Sebagaimana halnya pertumbuhan Tantrayana dalam Madzab ciwaisme, Mahayana dalam perkembangannya pecah menjadi beberapa Madzab. Diantara Madzab-Madzab Mahayana yang penting dan yang ada hubungannya dengan kitab Sang Hyang Kamahayanikan ini ialah Madzab Wajrayana atau Buddha Tantrayana kanan.

Dalam Tantrayana, pemujaan Tathagatha menduduki tingkat yang tertinggi, yaitu dalam apa yang disebut Anuttarayoga. Tingkat ini terbagi dalam dua bagian yaitu utpatti dan sampanna krama. Dalam utpatti-krama, melalui yoga, segala unsur dari badan, pikiran, perasaan, dan sifat manusia diproyeksikan sebagai lima unsur yang ideal, yaitu Panca Tathagatha. Ke lima tathagatha tersebut terdiri dari Vairocana, Ratnasambhawa, Amithaba, Amoghasidi, dan Aksobhya. Setelah proyeksi ini mencapai kesempurnaan, maka tingkat selanjutnya, yaitu sampanna-krama dapat dimasuki. Dalam tingkat ini, apa yang mula-mula merupakan bentuk proyeksi itu, diusahakan untuk diyakini sebagai suatu pengalaman yang hakiki dimana terjadi pengintegrasian antara badan pelaksana yoga dengan Tathagata, pikirannya dengan Tathagata dan demikian seterusnya sampai terjadi pengintegrasian yang menyeluruh dari sang pelaksana yoga dengan Tathagata.

Dengan lain perkataan, sang pelaksana Yoga bertranfigurasi dengan Tathagata menjadi Buddha. Perlu kiranya ditekankan disini, bahwa pencapaian ke-Buddhaan itu tiada ditujukan untuk kepentingan diri pribadi namun ditujukan bagi kebaikan orang lain. Melalui segala kemampuan yang luar biasa yang diperoleh sebagai akibat pencapaian ke-Budhaan itu, ia berusaha untuk menolong segala mahluk agar dapat mencapai KeBudhaan pula. (Magetsari Noerhadi, 1982).

Dengan tidak membeda-bedakan apa yang dianalisa, Sang Hyang Kamahayanikan juga dalam ajarannya mencoba menjelaskan teorinya 
itu dalam rangkaian memahami sifat dan hakekat Buddha sebagai asal Buddha yang disebut Adi Buddha dan merupakan faktor kehidupan dan yang menghidupkan seluruh alam semesta ini.

Sesuai penjelasan informan yang sudah diwawancarai yaitu Ida Pedanda Gede Nyoman Jelantik Dwaja dari Gria Jelantik Dauh Pasar Budakeling serta Ida Pedanda Gede Putra Kawan dari Gria Kawan Budakeling, dijelaskan bahwa praktek tantrisme di dalam aguron-guron menekuni jalan kerohanian dan telah memasuki tahapan layak menurut penilaian Guru atau Nabe. Menurut keterangan informan dalam proses upacara diksa, seorang calon diksa. Menurut informan yaitu Ida Pedanda Gede Nyoman Jelantik Dwaja dari Gria Jelantik Dauh Pasar Budakeling serta Ida Pedanda Gede Putra Kawan dari Gria Kawan Budakeling, upacara diksa mengandung kandungan Tantris yang kuat banhkan esensinya adalah Tantra.

Hal tersebut tampak saat prosesi "Napak"

\section{Diagram Jnana Buddha}

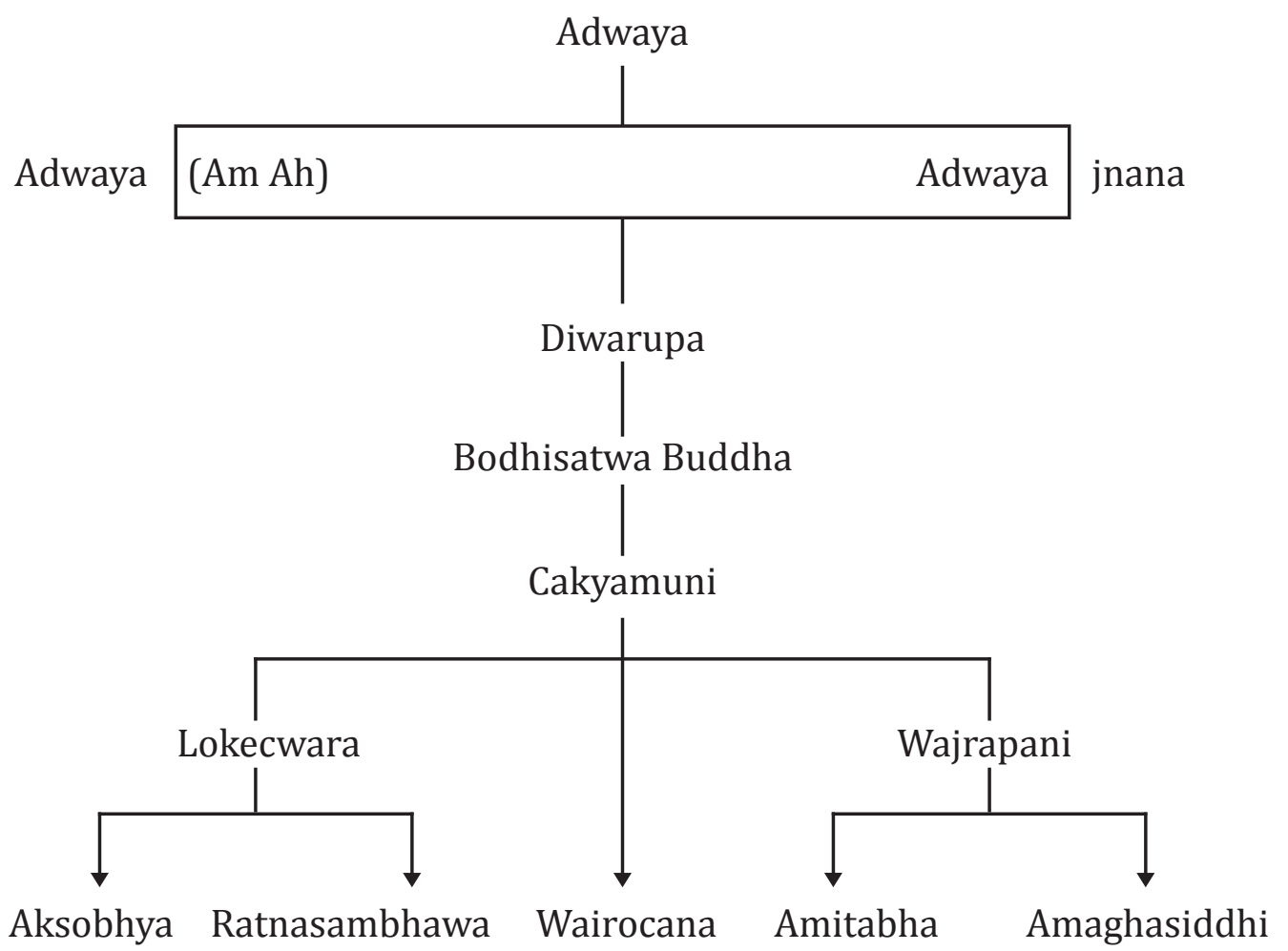

kawikon budha paksa di Gria Budakeling sesuai dengan kitab pegangan utamanya yaitu kitab Sang Hyang Kamahayanikan (SHK) yang merupakan kitab Budha Mahayana dari Mazhab Wajrayana yang bersifat/bercorak tantrisme. Disamping kitab SHK tersebut yang menjadi pegangan utama aguron-guron juga digunakan kitab-kitab dari paham kaSiwan sebagai penunjang.

\subsection{Upacara Diksa}

Secara umum diketahui upacara diksa adalah ritual inisiasi/apodgala/dwijati dari seorang calon diksa menjadi diksita. Upacara yang khusus diperuntukkan kepada sesorang yang dimana jempol kaki kiri diletakkan diatas ubunubun murid yang kemudian diikuti pengucapan mantra yang dilanjutkan rajah panca aksara. Hal tersebut adalah puncak dari 'Penciptaan', dan lahirnya sang putra dharma dari Garbha Jnana (rahimnya ilmu pengetahuan). Sesungguhnya murid/nanak lahir dari proses penyatuan atau pertemuan "ibu aksara" dan bapak "guru Nabe", yang merupakan perwujudan dari pertemuan sang hyang rwa bhineda. Itulah konsepsi ketantraan.

Menurut Arthur Avalon's dalam bukunya Mahanirwana Tantra, 1997, dijelaskan bahwa inisiasi (diksa) ialah saat pemberian mantra yang dilakukan oleh guru. Pada saat inisiasi itu 
dilakukan, guru menyatukan diri dengan 'shakti', yaitu menyerap Prana Shakti Guru yang bersthana di Sahasrara Chakra. Sebagai ciri kehadiranNya digunakan Yantra (praktik) yang dilekati oleh daya Shakti Dewata, demikian pun daya Shakti itu merasuk ke dalam diri Acharya yang melakukan inisiasi itu.

Sebelumnya, menurut Tantra, Acharya (guru) telah duduk bersama diatas tikar yang terbuat dari Kusha. Ia menguncarkan mantra (japa) tidur atau supta mantra di telinganya dan menutup ubun-ubunnya. Ketika itu murid berpuasa tidak melakukan hubungan seksual, kemudian mengulangi mantra yang diberikan itu tiga kali dan setelah itu sujud kehadapan guru. Inisiasi - inisiasi dilakukan untuk menyucikan diri lebih lanjut. Sebagaimana halnya sebuah lampu dinyalakan dengan menggunakan lampu lain, demikianlah Shakti itu dalam perwujudan mantra dipindahkan dari pribadi guru kepada Sisyanya.

\subsection{Upacara Pawisik}

Sebuah upacara yang merupakan rangkaian dari upacara Diksa, yang menurut penjelasan informan kami yaitu Ida Pedanda Gede Nyoman Jelantik Dwaja dari Gria Jelantik Dauh Pasar Budakeling serta Ida Pedanda Gede Putra Kawan dari Gria Kawan Budakeling, bahwanya upacara Pawisik merupakan upacara sakral dan bercirikan Tantra karena sangat dijaga kerahasiaanya. Upacara ini dilaksanakan tengah malam setelah proses diksa selesai dilakukan pada siang harinya. Prosesinya dimulai dengan menjemput Guru/Nabe oleh keluarga dari murid/nanak, kemudian Guru/Nabe diantar menuju atau memasuki kamar pribadi murid berdua bersama murid yang bersangkutan. Dalam keadaan pintu tertutup didalam ruangan Guru/Nabe berbicara empat mata dengan murid beliau yang mana materi pembicaraan tidak boleh diketahui oleh siapapun dan sang muridpun harus menjaga kerahasiaannya. Disitulah Guru/Nabe memberikan ajaran-ajaran yang sangat rahasya yang merupakan 'pusaka' turun temurun dari sebuah dynasty peguruan.

Hal tersebut sejalan dengan kitab Sanghyang Kamahayanikan yang dalam beberapa slokanya terdapat penjelasan tentang kewajiban menjaga kerahasyaan sebuah ajaran.

Sementara itu ada sebuah upacara yang merupakan bagian dari upacara kematian Guru/
Nabe, yang biasa disebut upacara Nilah yang menurut penjelasan informan kami yaitu Ida Pedanda Gede Nyoman Jelantik Dwaja dari Gria Jelantik Dauh Pasar Budakeling serta Ida Pedanda Gede Putra Kawan dari Gria Kawan Budakeling, bahwanya upacara Nilah ini merupakan upacara sakral dan bercirikan Tantra. Menurut informan lain, Ida Ketut Windia dari Gria Kawan Budakeling serta Ida Nyoman Wairocana dari Gria Tegeh Budakeling (wawancara tanggal, 20 Maret 2019), juga menyatakan hal yang sama, dimana tradisi Nilah pada upacara Nyiramang Layon, dilakukan sebagai bentuk bakti murid kepada Guru/Nabe, dimana murid merasa anugerah dari Guru tidak ternilai harganya, tidak bisa dilukiskan. Apabila murid berkelamin perempuan maka Nilah dilakukan dengan mencium jempol Kaki Kiri Guru/Nabe, dan apabila murid berjenis kelamin laki-laki, maka Nilah dilakukan dengan mencium Kelamin sang Guru/Nabe. Dimana "kelamin" diyakini sebagai symbol penciptaan sebagai penyebab kelahiran sang murid sebagai dwijati atau diksita. Demikan beliau menjelaskan.

Di Gria Budakeling apabila seorang Pedanda yang sudah menjadi Guru/Nabe meninggal maka pada saat upacara memandikan jenazah (nyiramang layon) akan dilanjutkan dengan tradisi upacara Nilah. Upacara ini diperuntukkan kepada para murid beliau, memberi kesempatan kepada para murid untuk menyampaikan bakti, penghormatan terakhir kepada sang Guru yang telah meninggal. Upacara dilakukan secara bergiliran oleh para murid dengan mencium jempol kaki kiri Nabe dan mencium kemaluan Nabe. Menurut informan kami yang mana beliau mengatakan sudah mewarisi tradisi ini yang ada sejak dulu kala, sebagai bentuk penghormatan dan ungkapan rasa bakti kepada sang Guru.

Tradisi-tradisi keTantraan memang sudah ada di Nusantara sejak jaman purba. Menurut Utama, I Wayan Budi (2014: 11), tradisi penggunaan symbol-simbol seks dalam hubungannya dengan hal-hal yang bersifat religius pada masyarakat Bali sudah dikenal sejak jaman purba seperti tampak pada arcaarca pemujaan yang bercorak megalitik. Ciri-ciri megalitik yang menonjol pada arca-arca dari masa Hindu di Pura Kebo Edan adalah hadirnya pahatan phallus (seks laki-laki) yang sangat besar. Ciri-ciri utama yang menunjukkan unsur prasejarah ini dapat ditelusuri melalui pahatan- 
pahatan dari tradisi zaman megalitik yaitu munculnya pahatan phallus dan vagina pada candi Sukuh menurut Linus,1978 (dalam Utama,2014). Menurut R.P. Soejono ( Redig, 1997, dalam Utama, 2014) phallus dianggap memiliki kekuatan gaib yang sangat besar.

Merujuk buku The Cult of Tara, Stephan Beyer (72, 1988), disebutkan bahwa didalam salah satu ritual Guhyasamaja tantra yang dilakukan di perguruan Trashilhunpo, ditemukan meditasi (visualisasi) berikut:

"before and behind my body, to the right and left, are the four sides of the mandala; my mouth and nose, anus and penis, are the four gates..."

"pada tubuh manusia dari kanan ke kiri dan dari depan dan belakang ada empat sisi dari mandala, mulut dan hidung, anus dan penis. Semua adalah 4 pintu gerbang"

Tubuh dalam keyakinannya adalah wujud yang sakral sebagai bentuk kebesaran Tuhan, serta mandala adalah ruang imajinatif semesta yang nantinya akan menjadi ruang para dewa.

Dari buku tersebut pada halaman 113 disebutkan sbb :

"In some ritual traditions the Great Bliss of the retinue takes the form of a "syllable off tarrfo-awareness" - either H U M or OM AH HUM- which, again, enters into the father and passes through his Vajra-penis and into the lotus-vagina of the mother, to be placed between two syllables $\mathrm{H} \mathrm{OH}$ before the deities dissolve; but in any event this "melted deity" - this "ball of Bliss" - is "aroused with song" to create the resultante Heruka, colored blue.

......"Dalam beberapa tradisi ritual "Kebahagiaan Sempurna" dijelaskan dengan bentuk "suku kata kesadaran tarrfo" apakah itu H U M or OM AH HUMdimana menyangkut Bapak (Purusa) dan melalui Vajra-penis dan melalui lotusvagina dari Ibu (Pradana), yg ditempatkan pada 2 suku kata $\mathrm{H} \mathrm{O} \mathrm{H}$ sebelum dewa itu larut, tapi dalam beberapa kejadian dewa yg larut itu "bola dari kesenangan" di rangsang dengan kidung utk mengasilkan Heruka berwarna biru.
Menurut buku, A Concise Introduction to Tibetan Buddhism, John Powers $(64,2008)$ disebutkan bahwa 'Penis' disamakan dengan Vajra.

Sementara menurut buku Indian Esoteric Buddhism, Ronald M. Davidson (197, 2003) disebutkan ;

"[we speak of] ignorance, anger and desire; but desire always is found in the Vajra [penis]. Thus the skillful means of the Buddhas is understood as Vajrayana"

"guhyasamaja tantra memproklamirkan bahwa (bila kita bicara) tentang ketidakpedulian, kemarahan dan hasrat; dimana hasrat itu selalu ditemukan di Penis (Vajra). Karena itu para ahli menganggap bahwa Buddha itu dipahami sebagai Vajrayana".

Di dalam desertasi Hariani Santiko, 7 Februari 1987 dengan judul "Kedududkan Bhatari Durga Di Jawa Pada Abad X - XV Masehi, (1987: 10) ada disebutkan dimana lambang Dewi Ibu banyak digunakan sekitar tahun 5000-4000 sebelum masehi dalam kaitan manusia memuja dewi kesuburan, dan terus berkembang sesuai kondisi peradaban masyarakat saat itu. Dalam perkembangan selanjutnya Dewi Ibu ini dipuja melalui berbagai aspeknya. Tiga bagian tubuh Dewi yakni payudara, perut dan alat kelaminnya , merupakan perlambang dari tiga aspek utamanya : payudara sebagai lambang Dewi Pelindung, pemelihara, serta sebagai sumber hidup manusia, perut adalah lambang sebagai penguasa kematian, dan alat kelamin adalah lambang Pencipta, (Srivastava 1979: 31).

Dari tiga tinjauan diatas tampak bahwa keturunan Brahmana Budha di Gria Budakeling berusaha menjaga kemurnian dan melakukan proses pemertahanan terhadap pakem, identitas dan tradisi-tradisi kebudhaannya yang mengandung ajaran Tantrisme.

\subsection{Implikasi Religius Magis}

Apabila melihat pengalaman para pelaku yogacara atau laku yoga yang diwawancarai bisa dilihat bahwa laku yoga sebagai bagian dari aguron-guron kawikuan budha paksa telah berimplikasi dalam hal magis atau mistis. Mereka menjadi memiliki kemampuan 'lebih' dibanding masyarakat pada umumnya. Sebuah 
kompetensi spiritual yang harus dimiliki seorang sulinggih bisa diraih dengan disiplin tinggi menjalankan laku yoga tersebut.

Jadi jelaslah bahwa kompetensi seorang wiku atau sulinggih haruslah sesuai dengan aguronguron budha paksa. Karena kekuatan Jnana beliau menjadi tumpuan masyarakat dalam halhal praktek yang bersifat magis. Untuk itu seorang wiku harus paham tentang Bajra Jnana (adwaya-adwaya jnana), sapta jatma, serta ajaran-ajaran rahasia lainnya. Tantrisme di dalam Aguron-guron Kawikuan Budha Paksa mensyaratkan agar calon wiku taat didalam laku yoga sehingga kesulinggihannya kelak dapat berguna buat masyarakat banyak dan semesta. Hal ini sesuai dengan informan Bape Made Degung (wawancara dilakukan di rumah beliau di dusun Wates Desa Bebandem Karangasem, 17 Maret 2019), beliau mengatakan system beragama manusia Bali cenderung terpusat kepada wiku atau pendeta, hal tersebut tampak pada puja surya sewana sang wiku yang sudah memohonkan kebaikan, kerahayuan semua umat manusia beserta seisi alam ini kepada Sang Hyang Surya, disamping itu setiap ritual keagamaan di Pura terjadi hal yang serupa. Hal ini menurut beliau karena ada dampak pada wilayah keyakinan keagamaan yang mendalam dari masyarakat akan kemampuan Jnana sang wiku atau pendeta. Merujuk kitab Sanghyang Kamahayanikan terbitan Proyek Penterjemahan Kitab Suci Hindu dan Buddha Departemen Agama R.I. tahun 1973 disebutkan bahwa salah satu akibat dari teori wajrayana mengajarkan bahwa ajaran Tantra tidak akan dapat dipelajari oleh sembarang orang tanpa mendapat petunjuk dari guru akhli yang telah mengetahui dan memiliki pengetahuan rahasia itu. Dengan sekedar membaca buku belumlah berarti seseorang telah dapat menemukan jalan yang benar sebelum mendapat pengajaran yang layak dari seorang guru spirituil akhli.

\subsection{Implikasi Sosial Religius}

Sementara dalam implikasi sosio religius menurut Koentjaraningrat (1985: 43-46; 1987: 80-83), kategori unsur-unsur utama sebuah agama terdiri dari lima bagian yaitu :

1. Emosi keagamaan (religious emotion), yaitu getaran jiwa yang menyebabkan manusia mempunyai sikap serba religi. Getaran jiwa ini antara lain, berupa sikap kagum dan terpesona terhadap hal yang gaib dan keramat yang kemudian diekspresikan dalam berbagai bentuk perilaku religius.

2. System keyakinan, yaitu wujud pikiran dan gagasan manusia yang menyangkut keyakinan dan konsepsi tentang Tuhan, dewa, roh, daya sakti, alam gaib (kosmologi), tercipta dan lenyapnya alam semesta (kosmogoni), kehidupan akhirat (eskatologi), dan lain-lainnya. Kecuali itu system keyakinan juga menyangkut system nilai dan norma keagamaan, baik lisan dan atau tertulis, yang berfungsi untuk mengatur tingkah laku penganutnya.

3. System ritual, yaitu berbagai wujud bakti atau wujud ekspresi penganutnya yang dilakukan pada waktu hari suci untuk melukiskan, memuliakan, memohon, mengadu, dan bersyukur kepada Tuhannya.

4. Tempat, waktu, sarana dan prasarana ritual. Dalam rangka mengekspresikan rasa baktinya itu, ia menggunakan tempat, waktu suci, dan berbagai sarana dan prasarana suci untuk melaksanakan aktifitas keagamaan dimaksud.

5. Umat agama, yaitu masyarakat yang menganut system keyakinan dan melaksanakan system ritus dan upacara yang diyakininya.

Pandangan relius berarti pandangan yang bersifat religi berupa timbulnya kepercayaan akan adanya kekuatan adikodrati di atas manusia.

Tantrisme di dalam aguron-guron ini memiliki implikasi religius dalam system keyakinan dan menumbuhkan pengetahuan dalam bidang Ketuhanan buat dunia kawikuan. Tantrisme telah membangun kesadaran-kesadaran dalam laku Yoga, bhawana dan catur arya satya, serta pertemuan adwaya dengan adwaya jnana. Menurut informan Ida Nyoman Wairocana (wawancara dilakukan di Pura Dalem Budakeling, 20 Maret 2019) bahwasanya tantrisme di dalam aguron-guron buddha paksa yang benar-benar dijalankan akan memberikan penguatan dalam hal menjaga tradisi dan mempertahankan identitas sebuah paham. Hal ini memiliki implikasi social religius dimana 
masyarakat pendukungnya akan termotivasi dan lebih yakin kepada ajaran warisan leluhurnya. Pemertahanan idenditas sangat dibutuhkan di jaman sekarang dan kedepannya. Dengan demikian keberadaan Wiku atau sulinggih dari paham Buddha Paksa akan memberi manfaat kepada masyarakat luas. Sementara menurut informan yang merupakan calon sulinggih Ida Wayan Oka dari Gria Tengah Budakeling (wawancara tanggal 28 Maret 2019), beliau mengatakan bahwa implikasi sosio religius dalam kaitan emosi keagamaan, aguronguron telah memupuk rasa bakti kepada guru/ nabe, yang nantinya akan menjadi acuan dalam implementasi ke masyarakat dalam bertindak (pelayanan) dan menjabarkan ajaran bakta itu sendiri. Rasa bakti tersebut memberi motivasi untuk lebih memahami ajaran dengan benar. Berkaitan pula dengan asewaka guru atau pengabdian kepada guru/nabe dimana rasa bakti tersebut memberikan dorongan untuk menjadi murid yang baik.

Sementara itu menurutnya, implikasi dalam kaitan dengan system keyakinan tantrisme didalam aguron-guron akan menambah rasa yakin terhadap kebesaran sebuah paham atau ajaran yang diyakini akan mampu mengantarkan kepada pembebasan. Paham tantrisme di dalam aguron-guron bila dikaitkan dengan system ritual, ini akan mendorong seorang untuk melakukan persiapan-persiapan yang bernuansa spiritual sebelum menjalankan sebuah ritual, hal ini untuk tercapainya tujuan sebuah ritual dengan baik. Seperti menjalankan Brata/puasa dimana semua itu didedikasikan kepada Tuhan.

Sementara menurut Ida Pedanda Gede Wayan Kerta Yoga, dari Gria Panji Budakeling, (wawancara dilakukan tanggal 3 April 2019), sebagai individu yang telah melewati masa pembelajaran, beliau menjelaskan bahwa implikasi social religius yang beliau rasakan adalah hidup beliau terasa lebih nyaman dan damai, penuh kasih yang dikarenakan oleh merasa berguna dalam kehidupan beragama masyarakat. Keberadaannya diperlukan untuk setiap yadnya yang ada. Beliau menjadi pelayan umat dengan tulus ikhlas.

Merujuk pada tesis dengan judul Sistem Kesulinggihan Teks Silkramaning Aguron-Guron Dan Aplikasinya Dalam Kehidupan Religius Di Bali, karya Citra, Ngurah Pratama (2012: 105) disebutkan bahwa implikasi social religius dimana setiap murid harus menghormati masyarakat, turut memohonkan kerahayuan jagat sehingga keberadaannya memiliki nilai positif pada masyarakat. Sementara keberadaan sulinggih harus dapat memberi manfaat kepada masyarakat sekitarnya. Ketentuan tersebut dinyatakan dalam beberapa teks.

Keseluruhan teks silakramaning aguronguron mengarahkan murid atau sisya agar memposisikan masyarakat sebagai pihak yang dihormati, dan mengabdi pada kepentingan masyarakat. Ketentuan tersebut secara jelas tersurat dalam teks diatas, serta tersirat dalam semua teks yang mengarahkan agar murid dan guru melaksanakan trikaya parisudha dan pengelolaan sang dasasila sehingga bermanfaat bagi dirinya dan menjadi teladan dalam masyarakat.

Menurut Citra, Ngurah Pratama (dalam Yasa serta Sukarma dan Budi Utama, ed, 2010: 195196), terdapat tiga tahap perkembangan pandangan religius masyarakat Bali, yaitu: 1) tahap teologis; 2) tahap metafisik; dan 3) tahap pengetahuan positif. Implikasi keberadaan tantrisme didalam aguron-guron kawikuan budha paksa pada tahap teologis dimaknai sebagai ajaran dari Shakti yang dalam hal ini Sanghyang Aji Saraswati yang menurunkan ilmu keagamaan, termasuk dalam mempelajari ilmu kasulinggihan.

Implikasinya bagi sisya dan guru adalah adanyaperilaku ritual sebagaisikap permohonan kepada-Nya agar memberikan restu untuk belajar. Tahap metafisik diwarnai dengan adanya tradisi Nyastra, untuk mencari tahu makna yang terkandung dalam teks-teks ketantraan, serta teks-teks lainnya yang mengatur tentang materi kesulinggihan dan mencari referensi yang lebih luas sehingga mudah dipahami dalam keseharian pembelajaran aspek kesulinggihan/kawikuan tersebut.

Tahap pengetahuan positif disikapi dengan membahas setiap teks tantrisme secara sitematis, objektif, empiris dan verifikatif, sehingga pesan moral religius yang disampaikan sebagai sesana dalam aguron-guron menjadi lebih mudah untuk dipahami.

Hal tersebut sesuai dengan rujukan-rujukan teks yang menjadi pegangan aguron-guron seperti yang telah diuraikan diatas. Kemudian diluar kontek 'guru-murid', implikasi social 
religius secara umum pada masyarakat adalah berjalannya proses pemertahanan pakem atau tradisi kesulinggihan Buddha Paksa di Gria Budakeling.

Secara teori yang dipakai dalam peneitian ini yaitu teori Resepsi, tampak terjadi penyambutan atau penerimaan oleh para calon wiku/sulinggih atau masyarakat secara umum, terhadap adanya paham tantris di dalam Aguron-guron Kawikuan Budha Paksa di Gria Budakeling. Dimana hal tersebut terlihat dari beragamnya pengalaman para informan yang berkaitan dengan religius magis serta social religius.

\section{PENUTUP}

Tantrisme di dalam aguron-guron kawikon budha paksa di Gria Budakeling merupakan inti dari ajaran kependetaan dari mazhab budha wajrayana, yang telah berlangsung sejak jaman dahulu serta diwarisi dan dipertahankan secara turun temurun oleh keturunan dari keluarga Gria Budakeling yang merupan keturunan dari Dang Hyang Astapaka seorang Pendeta Budha Kasogatan.

Sebagai sebuah system perguruan kependeta- an budha paksa, kitab Sang Hyang Kamahayanikan merupakan pegangan utama ditambah kitab-kitab dari siwa paksa seperti kitab silakramaning aguron-guron, silakrama, vrati sesana, siwa sesana dan lain-lain. Kitab Sang Hyang Kamahayanikan merupakan kitab kuno yang bersifat Tantris. Memuat ajaran filsafat jalan pembebasan, materi kependetaan serta tata aturan hubungan Guru/Nabe dan murid kerohaniannya.

Ciri penting dalam tantrisme tampak pada pemakaian mudra-asana adalah tingkat proses ke dua dalam pemakaian mantra. Walaupun mudra dan asana tampak sebagai satu bentuk berdiri sendiri, namun untuk membantu mantra-mantra yang bersifat rahasia wujud suara itu harus dibantu dengan simbul-simbul lahiriah berbentuk mudra atau pratima-pratima nyasa. Menurut ajaran Tantra, pelaksanaan ajaran kebaktian dalam agama harus meliputi semua aspeknya, yaitu: pikiran-suara-badan, yang kemudian kita kenal dengan istilah kaya (badan) - wak (kata-kata/suara) - citta (pikiran). Dari ke tiga proses itulah seseorang akan sampai pada samadhi.

\section{DAFTAR PUSTAKA}

Avalon's Arthur. 1997. Mahanirwana Tantra. Denpasar : Upada Sastra

Ayatrohaedi. 1986. Kepribadian Budaya Bangsa (Local Genius). Pustaka Jaya.

Basrowi Sukidin. 2002. Metode Penelitian Kualitatif. Insan Cendekia.

Citra, Ngurah Pratama. 2012. Sistem Kasulinggihan Teks Silakramaning Aguron Guron Dan Aplikasinya Dalam Kehidupan Religius Di Bali. Denpasar.

Desa Pakraman Budakeling. 2008. Awig-awig Desa Pakraman Budakeling.

Dharmopadesa Pusat. 2012. Sasana Aguron-guron. Denpasar.

Dinas Kebudayaan Provinsi Bali. 2006. Alih Aksara dan Bahasa Lontar Kusumadewa, Wrati Sasana, Wariga Krimping. Denpasar.

Hariani Santiko. 1987. Kedudukan Batari Durga di Jawa. Jakarta : Perpustakaan Nasional RI.

Hooykas, C.2017. Brahmana Bauddha di Bali. Udayana University Press.

Jelantik Dwaja, Ida Pedanda Gde Nyoman. 2011. Bancangah Dang Hyang Astapaka. Budakeling.

John Powers. 2008. A Concise Introdukcion to Tibetan Buddhism.

Kantor Kepala Desa Budakeling. 2017. Profil Desa Budakeling.

Kantor Dokumentasi Budaya Bali Provinsi Daerah Tingkat I Bali. 1996. Bhuwana Mahbah, Purwa

Bumi Kamulan Siwa Sasana, Sila Kramaning Aguron-Guron. Denpasar.

Koentjaraningrat. 2009. Sejarah Teori Antropologi. Universitas Indonesia (UI-Press)

Noerhadi Magetsari. 1982. Pemuja Tathagata di Jawa Pada Abad Sembilan. Jakarta : Perpustakaan

Nasional Republik Indonesia.

Ratna, Nyoman Kutha, SU.2004. Teori, Metode,dan Teknik Penelitian Sastra. Pustaka Pelajar. 
Ronald M. Davidson. 2003. Indian Esoteric Buddhism.

Sandika, I Ketut. 2019. Tantra Ilmu Kuno Nusantara. PT. Kaurama Buana Antara.

Sedyawati. Edi 2009. Saiwa dan Bauddha di Masa Jawa Kuna. Widya Dharma.

Suamba, I.B. Putu. 2007. Siwa - Buddha Di Indonesia. Widya Dharma. Stephan Beyer. 1998. The Cult of Tara.

Sugriwa, I Gusti Bagus. 2012. Sang Hyang Kamahayanikan. Denpasar : Pusat Kajian Bali Udayana University Press.

Surasmi, I Gusti Ayu. 2007. Jejeak Tantrayana di Bali, Denpasar : CV Media Adhikarsa.

Sutaba, I Made. 1980. Prasejarah Bali. B.U. Yayasan Purbakala Bali.

Panitya Penyusun Penterjemahaan. 1973. Sanghyang Kamahayanikan. Jakarta : Proyek Penterjemahaan Kitab Suci Hindu dan Buddha Departemen Agama R.I.

Utama, Budi I Wayan. 2014. "Orasi Ilmiah : Celak Kontong Lugeng Luwih". Denpasar : Universitas Hindu Indonesia.

Utama, Budi I Wayan. 2017. Pemaknaan Cerita Rakyat Brayut. Denpasar : Universitas Hindu Indonesia.

Utama, Budi I Wayan. 2017. Cerita Rakyat Brayut : Dari Ideologi Agraris Hingga Kapitalis, Jurnal Kajian Bali. 